\title{
Borsa İstanbul'da Sosyal Sorumlu Fiyatlama: Sürdürülebilirlik Endeksi Üzerine Bir Olay Çalışması
}

\author{
Serhat DURANAY \\ Isparta Uygulamalı Bilimler Üniversitesi, Eğirdir Meslek Yüksekokulu \\ serhatduranay@isparta.edu.tr \\ ORCID ID: 0000-0002-3090-2764 \\ Gamze GÖÇMEN YAĞCILAR \\ Süleyman Demirel Üniversitesi, İktisadi ve İdari Bilimler Fakültesi \\ gamzeyagcilar@sdu.edu.tr \\ ORCID ID: 0000-0002-5009-4696
}

\begin{tabular}{lrr} 
Araştırma Makalesi & DOI: $10.31592 /$ aeusbed.705880 \\
\hline Geliş Tarihi: 12.03 .2020 & Revize Tarihi: 23.09.2020 & Kabul Tarihi: 01.10.2020
\end{tabular}

\section{Atıf Bilgisi}

Duranay, S. ve Göçmen Yağcılar, G. (2020). Borsa İstanbul'da sosyal sorumlu fiyatlama: Sürdürülebilirlik endeksi üzerine bir olay çalışması. Ahi Evran Üniversitesi Sosyal Bilimler Enstitüsü Dergisi, 6(3), 903-917.

\section{ÖZ}

Yatırım kararları alınırken, ekonomik kriterlerin yanı sıra çevresel, sosyal ve yönetimsel faktörlerinde dikkate alındığ1 sürdürülebilir (sosyal sorumlu) yatırımlar dünya çapında gün geçtikçe daha çok ilgi çekmektedir. Türkiye'de de, Borsa İstanbul'da işlem gören ve kurumsal sürdürülebilirlik performansları üst seviyede olan şirketlerin yer alabilmesi amacıyla EIRIS ortaklığıyla BIST Sürdürülebilirlik Endeksi (XUSRD) oluşturulmuștur. Yatırımcilar, bu sayede sosyal, etik ve çevresel değerlerine uygun şirketlerin hisse senetlerine yatırım yapmak istediklerinde, XUSRD' yi rehber olarak kullanabilecektlerdir. Bu çalışmanın amacı, şirketlerin BİST Sürdürülebilirlik Endeksine alınması ve alınmamasına yönelik yatırımcıların tepkisini incelemektir. Bu amaçla, öncelikle 2018 ve 2019 yıllarında Endeks'te yer almak üzere ilk defa değerlendirmeye alınan şirketler endekse giren ve giremeyenler olmak üzere iki gruba ayrılmıştır. Ardından bu iki grupta yer alan şirketler üzerinden negatif ve pozitif tepkiler ölçülmüştür. Elde edilen sonuçlara göre, sürdürülebilirlik endeksine dahil edilmek kesin bir pozitif ya da negatif tepkiyle karşılanmamaktadır. Ancak, endekse girememek negatif bir tepkiyle doğurmuştur. Elde edilen bu sonuçlar, yatırımcıların şirketlerin sosyal, etik ve çevresel performanslarına karşı duyarlılıkları konusunda bilgiler sunmaktadır.

Anahtar Kelimeler: Sürdürülebilir yatırım, olay analizi, yatırımcı tepkisi, BİST Sürdürülebilirlik Endeksi.

\section{Social Responsible Pricing in Borsa Istanbul: A Case Study on Sustainability Index}

\begin{abstract}
Sustainable investing is an investment strategy that incorporates environmental, social and governance factors as well as economic criterias into investment decisions and gains more attention around the world. In Turkey, BIST Sustainability Index (XUSRD) has been launched in partnership with EIRIS in order provide a benchmark for Borsa İstanbul companies with high performance on corporate sustainability. This study aims to examine the reaction of investors to the stocks of the companies included (or not) in the BIST Sustainability Index. For this purpose, companies that were evaluated for the first time in 2018 and 2019 were divided into two groups, as those included in the index and those not, and negative and positive responses were measured. The results obtained show that inclusion of companies in the sustainability index does not meet with a definite positive or negative response, but exclusion from the index meets with a negative response. These results provide information on investor sensitivity to company's social, ethical and environmental performance.
\end{abstract}

Keywords: Sustainable investment, event study, investor response, BIST Sustainability Index.

\section{Giriş}

Sürdürülebilir yatırımlar, etik yatırım veya sosyal sorumlu yatırım olarak da bilinmekte (Renneboog, Ter Horst ve Zhang, 2008) ve yatırımcıların sosyal ve etik ilkelere dayanarak yatırım kararları almalarını ifade etmektedir. Sürdürülebilir yatırımların gelişimi, piyasaya yalnızca ekonomik ve finansal kriterlere dayanmayan yeni bir yatırım modeli sunmaktadır. Bu yatırım modeli, sürdürülebilir yatırım fonlarına, sürdürülebilir hisse senedi endeks ve varlıklarına odaklanmakta, 
yatırımcılara yatırım politikalarını kişisel değerleri ve ilkeleri ile karşılaştırma imkânı vermektedir (Domini, 2001; Ortas ve Moneva, 2011, s.396).

Günümüzde, sürdürülebilir yatırımlara yönelik dünya çapında Birleşmiş Milletler Sorumlu Yatırım Prensipleri (UN PRI), Birleşmiş Milletler Çevre Programı Finans Girişimi (UNEP FI) ve Karbon Saydamlık Projesi gibi kuruluşlar tarafından yönetilen ve yönlendirilen büyük bir ilgi vardır (Cheung ve Roca, 2013). Dünya genelinde, beş büyük piyasada (Avrupa, Amerika Birleşik Devletleri, Kanada, Japonya ve Avustralya/Yeni Zelanda) sürdürülebilir yatırım varlıklarının parasal tutarı son iki y1lda \%34 artış göstermiş ve 2018 yılında 30,7 trilyon dolar olarak gerçekleşmiştir. Sürdürülebilir yatırımlar günümüzde profesyonel olarak yönetilen varlıklar içerisinde önemli bir orana sahiptir. $\mathrm{Bu}$ oran, Japonya'da \% 18'den Avustralya/Yeni Zelanda'da \% 63'e kadar ulaşmaktadır (Küresel Sürdürülebilir Yatırım Raporu, 2018). Son yıllarda sürdürülebilir yatırımlarda gerçekleşen büyüme Tablol'de gösterilmiştir.

Tablo 1

2016 ve 2018 Yılları için Küresel Sürdürülebilir Yatırım Varlıkları

\begin{tabular}{lrr}
\hline Bölge & $\begin{array}{r}2016 \\
\text { (Milyar \$) }\end{array}$ & $\begin{array}{r}2018 \\
\text { (Milyar \$) }\end{array}$ \\
\hline Avrupa & 12.040 & 14.075 \\
ABD & 8.732 & 11.995 \\
Japonya & 474 & 2.180 \\
Kanada & 1.086 & 1.699 \\
Avustralya/Yeni Zelanda & 516 & 734 \\
Toplam & 22.838 & 30.683 \\
\hline
\end{tabular}

Kaynak: 2018 Küresel Sürdürülebilir Yatırım Raporu

Finans alanında sürdürülebilirlik konusuna olan ilgilin artması sonucu bir grup yatırımcının en iyi getirinin yanında şirketlerin sürdürülebilirlik performanslarını da öncelediği görülmüş; yatırımcıların şirketlerin hisse senetlerinin sürdürülebilirlik endeksine alınması ve kaldırılmasına nasıl tepki verdikleri sorusu da böylece araştırılan konular arasına girmiştir. Şirketlerin çevresel, sosyal ve yönetimsel faaliyetleri sosyal sorumlu yatırımcılar tarafından ödüllendirilirken, kötü sürdürülebilirlik performansları cezalandırılmaya devam ettikçe, kurumsal sürdürülebilirlik performansı hakkında bilgilerin yayınlanması ve yayılmasını sağlamak kamu politikasının da temel amaçlarından biri haline gelecektir (Oberndorfer, Schmidt, Wagner ve Ziegler, 2013, s. 497).

Sosyal sorumlu yatırımcılar, şirketleri kurumsal zayıflıklarını gidermeleri ve davranışlarını sosyal ve çevresel açıdan sürdürülebilir kılmaları için aşağıdan yukarıya doğru baskılamaktadırlar (Adriani ve Becchetti, 2002). Özellikle son y1llarda şirketler faaliyetlerinin yalnızca ekonomik boyutunu değil, çevresel ve sosyal boyutunu da kamuoyu ile paylaşmayı bir politika haline getirmişlerdir. Şirketlerin bu yöndeki eylemleri kurumsal sosyal sorumluluk (kss) olarak da adlandırılabilir. Kurumsal sosyal sorumluluk, şirketlerin sadece hissedarlarına karşı değil toplumun geri kalanına karşı da sorumlulukları olduğu anlayışına dayanmaktadır. Gelişmiş ülkelerde kurumsal sosyal sorumluluk anlayışının yerleşmesinde hem içsel işletme kararları hem de dişsal faktörler etkili olmaktadır. İçsel kararlar, şirketlerin kurumsal sosyal sorumluluk uygulamalarını rekabet stratejilerinin bir parçası haline getirmeleri olarak açıklanabilir. Günümüzde, farklı1ık yaratmanın rekabet avantajı oluşturabilmek için kaçınılmaz olduğu göz önünde bulundurulduunda, şirketlerin kurumsal sosyal sorumluluk bilincine sahip olmaları önemli bir farklılaşma unsuru yaratmaktadır (Çiftçioğlu ve Gök, 2018, s.184). Küresel çapta halka açık şirketlerin yaklaşı \% 70’i kurumsal sorumluluk alanında raporlama yapmaktadır. Ayrıca Global Fortune 250 listesinde yer alan ve 34 farklı ülkede yerleşik çok uluslu şirketlerin \% 95'inin çalışan hakları, çevre ve paydaş ilişkilerinde gerçekleştirdikleri faaliyet ve sonuçlarını, yıllık finansal raporlarıyla birlikte yayınladıkları görülmektedir (Şirketler için sürdürülebilirlik rehberi, BIST [Borsa İstanbul], 2014).

Sürdürülebilir hisse senedi endeksleri dünya genelinde şirketlerin çevresel, sosyal ve yönetimsel faaliyetleri, kurumsal sürdürülebilirlik performansları veya kurumsal sosyal sorumlulukları 
için uygun bir gösterge olarak kabul edilmektedir (Becchetti, Di Giacomo ve Pinnacchio, 2008). Borsa İstanbul'da işlem gören ve kurumsal sürdürülebilirlik performansları üst seviyede olan şirketlerin yer alabileceği bir endeks oluşturabilmek amacıyla da Ethical Investment Research Services Limited (EIRIS) ile yapılan anlaşma neticesinde BIST Sürdürülebilirlik Endeksi 4 Kasım 2014 tarihinden itibaren XUSRD koduyla hesaplanmaya başlanmıştır. EIRIS, yalnızca kamuya açık bilgileri kullanarak, Borsa İstanbul şirketlerini uluslararası sürdürülebilirlik kriterlerine göre değerlemeye tabi tutmaktadir.

Endeks, 2014 yılında BIST 30 Endeksi'nde yer alan şirketlerin değerlemeye alınmasıyla hesaplanmaya başlanmıştır. 2019 yılı itibariyle, BIST 100 veya BIST Sürdürülebilirlik endekslerinde yer alan şirketlerden gönüllü olanlar değerlemeye alınmaktadır. "Değerlemeye Tabi Şirketler Listesi" her yıl güncellenmekte ve aralık ayında Borsa İstanbul tarafindan ilan edilmektedir. Şirketlerin endekste yer alabilmeleri için, sürdürülebilirlik skorlarının "Endeks Seçim Kriterleri” ndeki eşik değerleri geçmeleri gerekmektedir (BIST Sürdürülebilirlik Endeksi Temel Kuralları, 2017). 2014 yılından itibaren BIST Sürdürülebilirlik Endeksinde yer alan şirket sayıları Tablo 2' de sunulmuştur.

Tablo 2

Yıllar İtibariyle BISST Sürdürülebilirlik Endeksinde Yer Alan Şirket Sayıları

\begin{tabular}{lrrrrrr}
\hline Dönemler & $\begin{array}{r}\text { Kasım 2014 } \\
\text { Ekim 2015 }\end{array}$ & $\begin{array}{r}\text { Kasım 2015 } \\
\text { Ekim 2016 }\end{array}$ & $\begin{array}{r}\text { Kasım 2016 } \\
\text { Ekim 2017 }\end{array}$ & $\begin{array}{r}\text { Kasım 2017 } \\
\text { Ekim 2018 }\end{array}$ & $\begin{array}{r}\text { Kasım 2018 } \\
\text { Ekim 2019 }\end{array}$ & $\begin{array}{r}\text { Kasım 2019 } \\
\text { Ekim 2020 }\end{array}$ \\
\hline $\begin{array}{l}\text { Değerlemeye } \\
\text { Tabi Şirketler }\end{array}$ & - & 50 & 63 & 63 & 71 & 61 \\
$\begin{array}{l}\text { Endekste Yer } \\
\text { Alan Şirketler }\end{array}$ & 15 & 29 & 43 & 44 & 50 & 56 \\
\hline
\end{tabular}

Kaynak: Borsa İstanbul duyurular, KAP duyurular

Tablo 2’ de görüldüğü üzere, yıllar içersinde sürdürülebilirlik endeksinde yer alan şirket sayılarında bir artış yaşanmaktadır. Bu durum hem endekse alınma kriterlerinde yapılan güncellemeler, hem de şirketlerin sürdürülebilirlik performanslarında yaşanan gelişmelerle açıklanabilir.

$\mathrm{Bu}$ araştırma, şirketlerin sürdürülebilirlik performansının yatırımcı kararları üzerindeki etkisine odaklanmıştır. Bu doğrultuda çalışmanın amacı, değerlendirmeye alınan ve bu değerlendirme sonucu BİST Sürdürülebilirlik Endeksi'ne giren ve giremeyen şirketlere yönelik yatırımcı tepkisinin yönünü ve şiddetini ortaya koyabilmektir. Ulaşılan sonuçlar sayesinde, yatırımcıların şirketlerin sürdürülebilirlik performansları hakkındaki düşünceleri ve tepkileri ile sosyal sorumlu yatırımcıların fiyatlama üzerindeki etkileri konusunda faydalı bilgiler elde edilmesi hedeflenmiştir.

$\mathrm{Bu}$ amaçlar doğrultusunda, Borsa İstanbul Sürdürülebilirlik Endeksi’nde ilk defa listelenmek üzere değerlendirmeye alınan şirketler incelenmiştir. Yatırımcı tepkisini daha iyi ölçebilmek adına iki farklı yıl üzerinden analizler gerçekleştirilmiştir. Ayrıca hem pozitif hem de negatif tepkileri tespit edebilmek için, değerlendirme sonucu endekse girmeye hak kazanan ve kazanamayan şirketlerin getirileri ayrı ayrı analiz edilmiştir.

Çalışmada, yatırımcı tepkisinin ölçülmesinde kullanılan olay çalışması metodolojisi, piyasanın tamamını bir bütün halinde ele alarak yahut her bir şirkete ayrı ayrı bakarak, farklı durumlar hakkındaki bilgilere yönelik piyasada oluşan tepkiyi ölçmek için oldukça fazla kullanılan bir yöntemdir. Bu çalışmada, sürdürülebilirlik endeksinde yer almanın şirketlerin hisse senedi getirileri üzerindeki etkisi incelendiği için, kurumsal sosyal sorumluluk ve sürdürülebilirlik ile ilgili piyasaya yansıyan haberler üzerinden yapılmış olan çalışmalara odaklanılmıştır.

Klassen ve McLaughlin (1996), şirketlerin kurumsal sosyal sorumluluk performansları ile finansal performansı arasındaki ilişkiyi incelemiştir. Çalışmada çevresel performansın göstergesi olarak, çevresel ödüller kazanan ve çevreyle ilgili olumsuz durumlar yaşayan şirketler hakkında çıkan duyurular kullanılmıştır. Elde edilen sonuçlar, güçlü çevresel yönetim sergileyen şirketlerin pozitif 
geri dönüşler aldığını, çevresel krizler yaşayan şirketlerin ise önemli negatif geri dönüşlerle karşılaştığını göstermektedir. Benzer bir çalışma aynı bakış açısıyla Lorraine, Collison ve Power (2004) tarafından Birleşik Krallık şirketleri için yapılmıştır. Elde edilen sonuçlar, özellikle şirketlerin almış olduğu çevresel ceza haberlerine piyasanın negatif tepki verdiğini ve bu tepkinin genellikle haberin yayınlanmasından 1 hafta sonra gerçekleştiğini ortaya koymuştur.

FTSE4Good UK Endeksi (Curran ve Moran, 2007) ve Dow Jones STOXX Sürdürülebilirlik Endeksi'nin (Ortas ve Moneva, 2011) incelendiği bazı çalışmalarda ise, toplumun çevresel ve sosyal performansa karşı kayıtsız kaldığı, sürdürülebilirlik endeksine girmenin ve endeksten çıkarılmanın günlük getiriler üzerinde anlamlı bir etki yaratmadığı ortaya konulmuştur. Ancak her ne kadar endekse giriş ve çıkış haberleri anlamlı bir tepkiyle karşılaşmasa da devamlı olarak sürdürülebilirlik endeksinde yer alan şirket hisselerine yönelik pozitif bir tepki doğmaktadır (Ortas ve Moneva, 2011).

Cheung ve Roca tarafından 2013 yılında geliştirilen Sürdürülebilirlik Kısıtı Hipotezi’ne göre hem endekse dahil edilen hem de endeksten çıkarılan şirketlerin hisse getirilerinde anlamlı bir düşüş yaşanmaktadır. Bu hipotez Dow Jones Global Sürdürülebilirlik Endeksi'ne dahil edilen ve çıkarılan Asya - Pasifik şirketleri üzerinde test edilmiş ve kabul görmüştür. Aynı yıl Alman şirketleri üzerinde yapılan bir başka araştırma sürdürülebilirlik endeksine dahil edilmenin negatif tepkiyle karşılaştığını ortaya çıkarmıştır. Oberndorfer vd.'nin (2013) yaptığı bu çalışmada, Dow Jones STOXX Sürdürülebilirlik Endeksi'ne (DJSI STOXX) dahil edilen şirketler negatif tepkiyle karşılaşmış ancak Dow Jones Global Sürdürülebilirlik Endeksi'ne giren şirketlere karşı anlamlı bir tepki tespit edilememiştir. Daszyńska-Żygadło, Ryszawska, Słoński ve Zawadzki (2014) ise STOXX Avrupa Sürdürülebilirlik Endeksi ve RESPECTS Endeksi'ni ele aldıkları çalışmada, duyuru günü negatif tepkinin ortaya çıtı̆̆g, olay günü ise bu tepkinin pozitif tepkiyle dengelendiği sonucuna ulaşmışlardır. Ayrıca 30 günlük uzun vadeli tepkinin de negatif olduğu tespit edilmiştir.

Piyasalarda, sürdürülebilirlik endeksine giriş ve çıkışlara yönelik bir tepkinin oluşmadığ 1 veya her iki durumda da negatif bir tepkinin oluştuğunu ortaya koyan çalışmalar olsa da temel hipotez, endekse girişlerde pozitif, endeksten çıkışlarda ise negatif bir tepkinin oluşacağı yönündedir. Consolandi, Jaiswal-Dale, Poggiani ve Vercelli (2009 Dow Jones Sürdürülebilirlik Endeksi), Reddy ve Gordon (2010, Yeni Zelanda Menkul Kiymetler Borsas1 - Avustralya Borsası) ve Robinson, Kleffner ve Bertels (2011, Dow Jones Sürdürülebilirlik Endeksi) tarafından elde edilen sonuçlar bu hipotezi doğrulamaktadır. Üstelik bu hipotezin gelişmekte olan piyasalarda da geçerli olduğu Varşova Menkul Kıymetler Borsası'nda işlem gören şirketlerin RESPECT Endeksi'ne girişleri üzerinden ortaya konulmuştur (Adamska ve Dabrowski, 2016). Ayrıca, pozitif anormal getiriler kısa sürede normale dönerken, negatif anormal getirilerin olay gününden sonra bir süre daha devam etmesi, borsada olumsuz sayılabilecek bir habere verilen tepkinin olumlu bir habere verilen tepkiden daha güçlü olduğunu da kanıtlamaktadır (Consolandi vd., 2009).

Becchetti, Ciciretti, Hasan ve Kobeissi (2012) tarafindan Domini 400 Social Index üzerinden yapılan çalışmada endekse girişlerde herhangi bir pozitif tepki oluşmazken yalnızca endeksten çıkış duyurularında negatif anormal getiri tespit edilmiş, buna karşın Nakai, Yamaguchi ve Takeuchi' nin (2013) Japon Morningstar Sosyal Sorumluluk Yatırım Endeksi'ni incelediği çalışmasında ise endekse dahil edilme pozitif anlamlı getiri sağlarken, endeksten çıkarılmanın anlamlı negatif bir etkisine rastlanılmamıştır. Bunun yanında, ilk yıllarda endekse girişlerde ortalama kümülatif anormal getiriler negatif iken ilerleyen yıllarda pozitife dönmektedir. Bu durum, yatırımciların sosyal sorumluluk kavramını yıllar içinde daha çok benimsemeleriyle ilişkilendirilebilir (Nakai vd., 2013).

Yabancı literatürde endekse girmeye, girememeye ve endeksten çıkarılmaya yönelik çok sayıda farklı çalışmaya rastlansa da hali hazırda bu alanda yapılan yerli çalışmaların sayısı kısıtlıdır. Ayrıca yapılmış olan bu kısıtlı çalışmalardaki odak nokta endekse dahil edilmenin etkileri olup, endeksten çıkarılma veya endekse dahil edilmeme durumlarının olası etkileri göz ardı edilmiştir. $\mathrm{Bu}$ bağlamda alanda yapılan yerli araştırmalar aşağıda sunulmuştur. 
Çıtak ve Ersoy (2016), yatırımcıların BİST Sürdürülebilirlik Endeksi'ne dahil olan şirketlere tepkisini hisse senedi getiri oranları ve Piyasa Değeri/Defter Değeri oranları üzerinden incelemiştir. Ortalama testleri sonuçlarına göre, sürdürülebilirlik endeksinde yer alan ve alamayan şirketlerin getiri oranı ortalamaları arasında anlamlı bir farklılık bulunamamıştır. Olay çalışması sonuçlarına göre ise, endekse dahil olan şirketlerin, açıklanma tarihinden 10 'ar gün öncesi ve sonrasında hiçbir gün için aşırı getiri oranı sıfırdan farklı çıkmamıştır. Ancak, açıklanma tarihinden sonraki 3 günlük periyotta endekste yer alan şirketlere yatırımcı tepkisinin olumlu ve anlamlı olduğuna dair bulgular elde edilmiştir.

Tükenmez ve Gençyürek (2016), Wilcoxon testi kullanarak, BİST Sürdürülebilirlik Endeksi'nde yer alan şirketlerin, endeksin lansmanı sonrası yaşadıkları fiyat değişimlerinin yönünü, Paired Sampel T testi yardımıyla da BİST Sürdürülebilirlik Endeksi ve BİST endeksleri arasındaki ilişkiyi incelemişlerdir. Çalışmada elde edilen bulgulara göre, çoğu şirketin fiyatları endekse dahil edildikten sonra düşüş göstermiştir. Ayrıca BİST Sürdürülebilirlik Endeksi ile diğer endeksler arasında anlamlı bir farklılık olmadığ tespit edilmiştir.

Altınay, Kaki, Kestane, Soba, Dinçer ve Eser, (2017), BIST Sürdürülebilirlik Endeksinde yer alan dört bankanın, sürdürülebilirlik endeksine girmeden önceki ve girdikten sonraki hisse senedi değişimlerini incelemişlerdir. Araştırmada, endekse girmenin banka performansı üzerinde olumlu bir etkisi olup olmadığı araştırılmış, bu kapsamda BİST100 Endeksi kapanış değerleri ile dört bankanın hisse senedi değerlerinin ağırlıklı ortalamalarının ay sonu değerleri kullanılmıştır. Çalışmada ilk olarak dört bankanın hisse senedi değerleri ortalaması ile BİST100 kapanış değerleri arasındaki ilişki Pearson korelasyon analizi ile incelenmiş, değişkenler arasında pozitif yönlü anlamlı ilişki bulunmuştur. Sürdürülebilirlik endeksine dahil olunmasından öncesi ve sonrası ortalama değerler arasında ise istatiksel olarak anlamlı bir farklılık bulunamamıştır. Sürdürülebilirlik endeksine dahil olunduktan sonra, ortalama getirilerde bir azalış gerçekleşmiş olsa da, bu azalış anlamlı değildir.

Temiz ve Acar (2018), BİST Sürdürülebilirlik Endeksi'nde yer alan 44 şirketin, endekse giriş duyurusunun hisse senedi getirisi üzerinde aşırı bir etkiye sahip olup olmadığını ölçmek için olay çalışması yöntemi kullanmışlardır. Çalışmada elde edilen sonuçlara göre, endekse girme duyurusunun hisse senedi getirisi üzerinde aşırı tepkiye neden olduğuna dair kısıtlı kanıtlara ulaşılmıştır. Olay günü $\% 10$ anlamlılık seviyesinde negatif aşırı getiri ortaya çıkmış, olay sonrası ise yalnızca üç günde anlamlı aşırı getirilere rastlanmış, bu getiriler iki gün negatif bir gün ise pozitif olarak gerçekleşmiştir. Ayrıca, toplam varlık, hisse başı kar, borçluluk ve Tobin Q değerlerine göre sınıflandırılan şirketlerin aşırı getirileri arasında anlamlı bir farklılık tespit edilememiştir.

Gök ve Gökşen de (2020) çalışmalarında BİST Sürdürülebilirlik Endeksi'nde işlem gören bankalara odaklanmışlardır. Endekse giriş duyurularının, getiri üzerindeki etkilerinin olay çalışması yöntemiyle araştırıldığ çalışma, XUSRD'de Kasım 2014 - Ekim 2019 arasında ortaya çıkan ortalama anormal getirilerin genel olarak duyuru öncesinde negatif, duyuru sonrasında ise pozitif olduğunu göstermiştir. Kümülatif ortalama anormal getiriler (CAAR), olaydan 10 gün öncesinden olay gününe kadar negatif olarak giderek artış göstermiş, olay gününden itibaren ise düzelme başlamış ve olaydan 10 gün sonrasında ilk kez pozitif değer ortaya çıkmıştır. Olaydan 10 gün sonrası ve 10 gün öncesindeki CAAR değerleri arasındaki ortalama fark pozitiftir ve istatistiksel olarak anlamlıdır. Çalışmadan elde edilen bulgular, bankaların XUSRD'de listelenmelerinin, yatırımcılar açısından pozitif bir etki yarattığına işaret etmektedir.

Ulaşılan literatür değerlendirildiğinde, özellikle Türkiye için yapılan çalışmalarda endekse girmenin şirketlerin hisse senetleri üzerindeki etkisinin anlamlı olduğuna dair kısıtlı sonuçlar elde edildiği görülmektedir. Ne var ki piyasanın negatif haberlere pozitif haberlerden daha büyük tepki verdiği de bilinen bir durumdur. Bu bağlamda şirketlerin endeksten çıkartılmalarının ya da değerlendirmeye alınıp endekse kabul edilmemelerinin etkisinin araştırılması noktasında literatürde boşluk olduğu görülmektedir. 


\section{Yöntem}

Şirketlerin BİST Sürdürülebilirlik Endeksi (XUSRD) açısından değerlendirmeye alınmasının ve bu değerlendirmenin ardından endekse kabul edilip edilmediğine ilişkin bilginin kamuoyuna duyurulmasının ardından şirketlerin getirilerinde anlamlı değişimler olup olmadığının araştırılması için "Olay Analizi” yöntemi kullanılmıştır. Yöntem, bir hisse senedinin belirli bir olaya verdiği fiyat tepkisini analiz etmek için kullanılmaktadır (Scholtens ve Peenstra, 2009, s. 3232). Çalışmada kullanılan Olay Analizi yöntemi, spesifik bir olay ya da bilgiye ilişkin haberin piyasaya ulaşmasını takiben yatırımcının verdiği kısa süreli tepkiyi ölçmek için kullanılan etkili bir yöntemdir. Buna göre olay günü etrafında gerçekleşen getiriler, beklenen getirilerden anlamlı bir farklılık gösteriyorsa, piyasada söz konusu olaya tepki olarak Anormal Getiri (AR) oluşmuş demektir. Bu doğrultuda duyurunun yapıldığı gün "olay günü” olarak kabul edilmiş ve olay gününü takip eden günlerde şirket hisselerinin anormal getiriler sağlayıp sağlamadığı değerlendirilmiştir. Gerçekleșen getirilerin "anormal" olup olmadığına karar verilebilmesi için öncelikle karşılaştırma yapılabilecek şekilde "beklenen getirilerin" oluşturulması gerekmektedir. Olay analizi de esasında gerçekleşen getirilerin beklenen getiriden anlamlı bir sapma gösterip göstermemesi durumuna göre "olay etkisinin" varlığını araştırmaya dayanmaktadır.

Piyasa verilerine dayalı olay çalışmalarında beklenen getirilerin hesaplanması genellikle piyasa modeli referans alınarak yapılmaktadır. Bu amaçla "Olay Penceresi" olarak adlandırılan, olay etkisinin beklendiği zaman aralığ için beklenen getiriler, olay penceresinden önceki belirli bir zaman diliminde (tahmin penceresi) gerçekleşen getiriler bağlamında hesaplanmaktadır.

Olay analizi, "Olay Penceresi" ve "Tahmin Penceresi" olarak adlandırılan periyodların tespit edilmesinin ardından, 5 adımdan oluşan bir hesaplama süreci izlenerek gerçekleştirilir. Çalışmada "Olay Penceresi" olarak, Sürdürülebilirlik Endeksi'nde yer alan şirketlerin ilan edildiği "Olay Günlerinden" önceki ve sonraki on beşer günü kapsayan toplam 31 günlük dönem alınmıştır. Olay penceresinden önceki 200 gün ise "Tahmin Penceresi'ni" oluşturmaktadır. Olay analizi tekniğinin uygulanmasinda Yavuz, Yildırım ve Elmas (2015, s.78-79) ile Brown ve Warner (1980)'in uyguladıkları yöntemler takip edilmiştir. İlk adım, olay penceresi içerisinde her bir şirketin her bir gün için anormal getiri elde edip etmediğinin tespit edilmesidir. Bu amaçla, tahmin penceresi boyunca endeks getirilerine ve şirketin getirilerine ilişkin zaman serileri regresyona tabi tutulur. Bunun için öncelikle endeksin ve hisse senetlerinin günlük getirilerinin hesaplanması gerekmektedir. Denklem (1) piyasa getirisinin, Denklem (2) ise hisse senedi getirilerinin hesaplanmasında kullanılmaktadır.

$R_{m t}=\frac{I_{t}-I_{(t-1)}}{I_{(t-1)}}$

Denklem (1)'de $R_{m t}$, piyasa getirisini, $I_{t}$ BIST100 endeksinin t günündeki kapanış değerini ve $I_{(t-1)}$ BIST100 endeksinin t-1 günündeki kapanış değerini ifade etmektedir.

$R_{i t}=\frac{D+\left(P_{i t}-P_{(i t-1)}\right)}{P_{(i t-1)}}$

Denklem (2)'de $R_{i t}$ hisse “ $i$ ” senedinin $t$ günündeki getirisini; $P_{i t}$ şirketin hisse senedinin $t$ günü kapanış fiyatını, $\mathrm{P}\left({ }_{\mathrm{it}-1)}\right.$ " $\mathrm{i}$ ” hisse senedinin $\mathrm{t}-1$ günü kapanış fiyatını ve " $\mathrm{D}$ " ise hisse senedinin $\mathrm{t}$ gününde ödenen kar payını ifade etmektedir.

Denklem (1) ve Denklem (2)'nin çözümünden elde edilen günlük getiriler her bir hisse senedi için Denklem (3)'te gösterilen regresyon analizine tabi tutulmuştur. Böylece elde edilen sabit terim $(\alpha)$ ve regresyon katsayısı $(\beta)$, beklenen getirilerin hesaplanmasında kullanılmaktadır.

$R_{i t}=\alpha_{i}+\beta_{i} R_{m t}+\varepsilon$

Regresyon analizinden (Denklem (3)) elde edilen regresyon katsayısı ve sabit terim, olay penceresi için kurulan piyasa modelinde endeks getirisi ile birlikte şirketin beklenen getirisinin, yani $\mathrm{E}(\mathrm{R})_{\mathrm{it}}$ 'nin hesaplanmasında kullanılmaktadır (Denklem (4)). 


$$
E(R)_{i t}=\alpha_{i}+\beta_{i} R_{m t}
$$

Şirketin beklenen getirileri hesaplandıktan sonra, olay penceresi boyunca gerçekleşen getiriler ile beklenen getiriler arasındaki fark, şirketin anormal getirisini oluşturmaktadır (Denklem (5)).

$A R_{i t}=R_{i t}-E(R)_{i t}$

Anormal getiriler her bir şirket için günlük olarak Denklem (5)'teki gibi hesaplanabilir. Ancak istatistiksel olarak anlamlı bir anormal getirinin varlığından söz edebilmek için, anormal getirilerin t istatistiklerinin hesaplanması ve kritik değerler ile karşılaştırılması gerekmektedir. Hesaplanan anormal getirilerin, tahmin penceresinde analiz edilen regresyon modelinin standart hatasina $(\sigma)$ bölünmesi ile $\mathrm{t}$ istatistiği elde edilmiş olur (Denklem (6). T istatistiğinin değerinin, kritik değerler olan $\pm 1,96$ ' dan $( \pm 1,645)$ mutlak değerce büyük olması, anormal getirinin \% $5(\% 10)$ anlamlılık düzeyinde anlamlı olduğu şeklinde yorumlanır.

$$
t(A R)=\frac{A R_{i t}}{\sigma_{i}}
$$

Ortalama anormal getiriler (AAR), her bir olaya dahil olan şirketlerin, olay penceresinin ilgili günündeki anormal getirilerinin aritmetik ortalamasıdır. AAR, belirli bir şirkete ya da şirket grubuna yatırım yapan yatırımcının olay penceresi içerisindeki belirli bir günde elde edeceği günlük anormal getirisini ifade eder. Denklem (7)'de AAR'nin hesaplanışına yer verilmiştir. Ortalama anormal getirilerinin sıfırdan farklı olup olmadığının anlaşılması için Denklem (8)'den yararlanılır. Denklem (7) ve Denklem (8)'de " $n$ " şirket sayısını göstermektedir.

$$
\begin{aligned}
& A A R_{t}=\left(\frac{1}{n}\right) \sum_{i=1}^{n} A R_{i t} \\
& t\left(A A R_{t}\right)=\left(\frac{1}{\sqrt{n}}\right) \sum_{i=1}^{n} \frac{A R_{i t}}{\sigma_{i}}
\end{aligned}
$$

Olay gününün öncesinde ve sonrasında yatırımcının dönemsel toplam getirisinin beklenenden farklı olup olmadığının ölçülebilmesi için kümülatif ortalama anormal getirilerin (CAAR) hesaplanmasına ihtiyaç duyulmaktadır. Ortalama anormal getirilerden yararlanılarak CAAR hesaplanmasında Denklem (9) kullanılmaktadır. CAAR'ın anlamlılığının test edilmesi için kullanılacak t istatistiğinin formülü, Denklem (10)'da gösterilmiştir. "k" serbestlik derecisi olup, "n-2" alınmıştır.

$$
\begin{aligned}
& C A A R=\left(\frac{1}{n}\right) \sum_{t=T_{1}}^{T_{2}} \sum_{i=1}^{n} A R_{i t} \\
& t(C A A R)=\frac{\operatorname{CAAR}\left(T_{1}, T_{2}\right)}{\sigma_{C A A R\left(T_{1}, T_{2}\right)}} \\
& \sigma_{C A A R}=\sqrt{\frac{1}{N(N-d)} \sum_{i=1}^{N}\left(C_{A} A R_{i}\left(T_{1}, T_{2}\right)-\operatorname{CAAR}\left(T_{1}, T_{2}\right)\right)^{2}}
\end{aligned}
$$

Denklemde d serbestlik derecesi olup, piyasa modeli için n-2 olarak alınmıştır.

\section{Veri Seti ve Araştırmanın Sınırlılıkları}

$\mathrm{Bu}$ çalışmanın amacı yatırımcıların şirketlerin sürdürülebilirlik endeksine girdiklerine/giremediklerine ilişkin piyasaya ulaşan bilgiye tepki verip vermediklerinin; diğer bir ifadeyle yatırımcıların şirketlerin endekste yer almalarına duyarlı olup olmadıklarının tespit edilmesidir. Bu bağlamda; şirketlerin sürdürülebilirlik endeksinde yer almalarının performanslarını ne şekilde etkilediği farklı analiz teknikleri kullanılarak incelenebilse de araştırmanın amacına en uygun yöntem olarak Olay Analizi metodu seçilmiştir. Spesifik bir olay ya da bilgiye ilişkin haberin piyasaya ulaşmasını takiben yatırımcının verdiği kısa süreli tepkiyi ölçmede Olay Analizi’ nin sıklıkla başvurulan bir yöntem olduğu farklı çalışmalarda (Bash ve Alsaifi, 2019, Faramarzi ve Bhattacharya, 2021, Kim, Kim, Lee ve Thang, 2020, Pandey ve Kumari, 2001, Yue, Zhang ve Zhang, 2020) rahatça görülebilmektedir. 
Analizde kullanılacak veriler, 2018 ve 2019 yılları için BİST Sürdürülebilirlik Endeksi’nde yer almak üzere ilk defa değerlendirmeye alınan şirketlerin gün sonu kapanış verileridir. Kasım 2017Ekim 2018 döneminde, 63 şirket değerlendirmeye alınmış olup bunların 23 tanesi, Kasım 2018-Ekim 2019 döneminde ise 71 şirket değerlendirmeye alınmış olup bunların 27 tanesi bir önceki dönemlerde endekste yer almamış şirketlerdır. Olay günleri 27.10.2017 ve 26.10.2018 olup ilk olay tarihi için 23 şirketin, ikinci olay tarihi için ise 27 şirketin, olay penceresi için 31 günlük, tahmin penceresi için ise 200 günlük olmak üzere kapanış verileri Bloomberg Terminal üzerinden elde edilmiştir.

\section{Bulgular}

Çalışmada olay günü olarak iki farklı tarih ele alınmıştır. Bu tarihlerden ilki, 2018 yılı için BİST Sürdürülebilirlik Endeksi’nde yer alacak ve alamayacak şirketlerin açıklandığ 127.10 .2017 günü, ikinci tarih ise, 2019 yllında endekste yer alacak ve alamayacak şirketlerin açıklandığ 26.10 .2018 günüdür. Her bir dönem için şirketlerin XUSRD'ye girmelerinin ya da girememelerinin ilanı, bağımsız birer olay kabul edilmiştir. Dolayısıyla, 4 ayrı olay analizi gerçekleştirilmiştir.

27.10.2017 günü açıklanan sonuçlara göre, 5 şirketin 2018 yılında XUSRD'de yer alacağı duyurulmuştur. Bu 5 şirketin 3 tanesinde olay penceresinin farklı günlerinde $\% 5$ ve $\% 10$ anlamlıllk düzeylerinde anormal getiriler tespit edilmiştir. Diğer iki şirketin anormal getirilerinin anlamlılık seviyesi \% 10'dur.

27.10.2017 günü endekse giremeyeceği duyurulan 18 şirketin 12 tanesinde farklı günlerde $\% 5$ ve $\% 10$ anlamlılık seviyelerinde, ilave olarak 4 tanesinde $\% 10$ anlamlllık seviyesinde anormal getiriler gözlenmiş̧tir. Bu şirketler arasında anormal getiriye rastlanmayan şirket sayısı 2’dir.

26.10.2018 günü açıklanan sonuçlara göre 2019 yılı değerlendirme sonuçlarına göre 6 şirketin XUSRD'de yer alacağ 1 ilan edilmiştir. 3 şirkette $\% 5$ ve \% 10 seviyelerinde, 2 şirkette yalnızca \% 10 seviyesinde anlamlı anormal getiri tespit edilmiştir. Bir şirketin ise anormal getiri sağlamadığı anlaşılmışıtır.

26.10.2018 günü ilan edilen sonuçlara göre, 21 şirketin 2019 y1lında XUSRD'de yer almayacağı duyurulmuştur. Bu şirketlerin 11 tanesinde $\% 5$ ve $\% 10$ anlamlılık seviyelerinde, 6 tanesinde ise yalnızca \% 10 anlamlılık seviyesinde anormal getiri görülmüştür. Yalnızca 4 şirkette anormal getiriye rastlanmamıştır.

Buraya kadarki değerlendirmeler, şirket bazlı ve günlük anormal getirileri içermektedir. Ortalamalar dikkate alınarak hesaplanan ortalama anormal getirilere ilişkin Tablo 3'e bakıldığında, endekste yer almayacağı duyurulan şirketlerin endekse giren şirketlere kıyasla çok daha fazla sayıda ortalama anormal getiri sağladığı görülmektedir. Bu bulgu, finansal piyasalarda negatif bilginin pozitif bilgiye göre daha fazla tepkiyle karşılaştığı yönündeki genel kanı ile uyumludur. Anlamlı anormal getirilerin ağırlıklı olarak olay gününün sonrasında ortaya çıktığı göze çarpmaktadır. 27.10.2017 tarihinde endekse giremeyen şirketlerin, $\mathrm{t}+1$ günü dışındaki tüm anormal getirileri negatiftir. 26.10.2018 tarihinde endekse giremeyen şirketler ilk gün negatif anormal getiri sağlamış, $\mathrm{t}+10$ gününden itibaren ise anormal getiriler pozitife dönmüştür. Endekste yer almayan şirketlerda ortalama anormal getiriye rastlanmamıştır.

Tablo 3

Ortalama Anormal Getiriler (AAR)

\begin{tabular}{rrrrr}
\hline & 27.10 .2017 & 27.10 .2017 & 26.10 .2018 & 26.10 .2018 \\
& Giren & Giremeyen & Giren & Giremeyen \\
\hline $\mathrm{T}(+15)$ & $-0.0141^{* *}$ & $-0.0123^{* *}$ & $0.0209 * *$ & 0.0011 \\
$\mathrm{~T}(+14)$ & 0.0029 & -0.0025 & -0.0078 & -0.0035 \\
$\mathrm{~T}(+13)$ & 0.0057 & $-0.0073 *$ & -0.0029 & $0.0121^{* *}$ \\
$\mathrm{~T}(+12)$ & 0.0070 & -0.0010 & -0.0043 & -0.0046
\end{tabular}




\begin{tabular}{rrrrr}
$\mathrm{T}(+11)$ & 0.0011 & $-0.0110^{* *}$ & -0.0092 & $0.0060^{*}$ \\
$\mathrm{~T}(+10)$ & -0.0050 & -0.0002 & -0.0134 & $0.0324^{* *}$ \\
$\mathrm{~T}(+9)$ & 0.0019 & 0.0062 & -0.0088 & 0.0050 \\
$\mathrm{~T}(+8)$ & 0.0040 & 0.0024 & 0.0080 & 0.0011 \\
$\mathrm{~T}(+7)$ & 0.0026 & 0.0012 & 0.0027 & 0.0021 \\
$\mathrm{~T}(+6)$ & -0.0015 & $-0.0061^{*}$ & 0.0059 & -0.0066 \\
$\mathrm{~T}(+5)$ & -0.0085 & -0.0002 & 0.0025 & $-0.0070^{* *}$ \\
$\mathrm{~T}(+4)$ & 0.0025 & $-0.0122^{* *}$ & -0.0060 & -0.0045 \\
$\mathrm{~T}(+3)$ & -0.0047 & -0.0010 & -0.0005 & -0.0037 \\
$\mathrm{~T}(+2)$ & 0.0027 & $-0.0175^{* *}$ & -0.0014 & $-0.0142^{* *}$ \\
$\mathrm{~T}(+1)$ & 0.0040 & $0.0066 *$ & -0.0014 & -0.0072 \\
\hline $\mathrm{T}(0)$ & -0.0078 & -0.0104 & 0.0069 & 0.0037 \\
\hline $\mathrm{T}(-1)$ & 0.0073 & 0.0059 & $-0.0209 * *$ & 0.0016 \\
$\mathrm{~T}(-2)$ & 0.0027 & -0.0017 & -0.0019 & $-0.0113 * *$ \\
$\mathrm{~T}(-3)$ & 0.0093 & -0.0061 & 0.0042 & -0.0040 \\
$\mathrm{~T}(-4)$ & $0.0100 *$ & 0.0038 & -0.0138 & -0.0050 \\
$\mathrm{~T}(-5)$ & -0.0051 & 0.0059 & 0.0013 & 0.0031 \\
$\mathrm{~T}(-6)$ & 0.0040 & -0.0037 & 0.0035 & 0.0051 \\
$\mathrm{~T}(-7)$ & 0.0006 & -0.0016 & 0.0052 & -0.0004 \\
$\mathrm{~T}(-8)$ & 0.0001 & 0.0017 & 0.0120 & 0.0021 \\
$\mathrm{~T}(-9)$ & 0.0013 & 0.0000 & 0.0088 & 0.0061 \\
$\mathrm{~T}(-10)$ & -0.0006 & 0.0002 & -0.0013 & 0.0017 \\
$\mathrm{~T}(-11)$ & -0.0061 & -0.0086 & -0.0061 & -0.0017 \\
$\mathrm{~T}(-12)$ & -0.0001 & -0.0009 & -0.0056 & 0.0006 \\
$\mathrm{~T}(-13)$ & 0.0098 & $-0.0150 * *$ & 0.0000 & -0.0045 \\
$\mathrm{~T}(-14)$ & -0.0065 & $-0.0143 * *$ & -0.0056 & -0.0018 \\
$\mathrm{~T}(-15)$ & -0.0045 & -0.0045 & -0.0019 & 0.0036 \\
\hline$\%$ & 0.960
\end{tabular}

Not: ** ve * sirasıyla $\% 5$ ve $\% 10$ anlamlılık seviyelerinde anlamlı olan değerli ifade etmektedir.

Tablo 4 ise endekse giren ve giremeyen şirketlere ait, olay gününden önceki ve sonraki beșer gün $(-5 ;+5)$, önceki 5 gün $(-5 ; 0)$ ve sonraki 5 günlük $(0 ;+5)$ Kümülatif Ortalama Anormal Getirileri (CAAR) göstermektedir.

Tablo 4

Kümülatif Ortalama Anormal Getiriler (CAAR)

\begin{tabular}{rrrrr}
\hline & 27.10 .2017 & 27.10 .2017 & 26.10 .2018 & 26.10 .2018 \\
& Giren & Giremeyen & Giren & Giremeyen \\
\hline$(0 ;+5)$ & -0.0119 & $-0.0348^{* *}$ & 0.0000 & $-0.0329^{* *}$ \\
$(-5 ;+5)$ & $-0.0137^{* *}$ & 0.0057 & $-0.0311^{* *}$ & $-0.0484^{* *}$ \\
$(-5 ; 0)$ & 0.0164 & -0.0027 & -0.0242 & -0.0118 \\
\hline
\end{tabular}

Not: ** ve * sirasıyla $\% 5$ ve $\% 10$ anlamlılık seviyelerinde anlamlı olan değerli ifade etmektedir.

Tablo 4'te yer alan bulgular 27.10.2017 tarihinden 5 gün önce endekse giren veya giremeyen şirketlere yatırım yapan yatırımcıların olay gününe kadarki 5 günlük süreçte anlamlı bir getiri elde edemediklerini göstermektedir. Olay günü endekse giren şirketlere yatırım yapan ve yatırımlarını olay gününden 5 gün sonraya kadar uzatan yatırımcılar da herhangi bir anlamlı getiri elde edemezken endekse giremeyen şirketlere yatırım yapan ve yatırımlarını 5 gün uzatan yatırımcılar negatif ve $\%$ 3,48 getiriyle karşılaşmışlardır. Aynı olay için bakıldığında, olay gününden 5 gün önce yatırım yapan ve yatırımlarını olay gününden 5 gün sonrasına kadar uzatan yatırımcılardan, endekse giren şirketlere yatırım yapanların negatif ve \% 1,64 getiriyle karşılaştıkları buna karşılık endekse giremeyen şirketlere yatırım yapanların ise anlamlı bir getiri elde edemedikleri tespit edilmiştir.

26.10.2018 tarihli olayda da olay tarihinden 5 gün önce endekse giren veya giremeyen şirketlere yatırım yapan yatırımcıların olay gününe kadarki 5 günlük süreçte anlamlı bir getiri elde edemedikleri tespit edilmiştir. Olay günü endekse giren şirketlere yatırım yapan ve yatırımlarını olay gününden 5 gün sonraya kadar uzatan yatırımcılar herhangi bir anlamlı getiri elde edemezken endekse 
giremeyen şirketlere yatırım yapan ve yatırımlarını 5 gün uzatan yatırımcılar negatif ve $\% 3,29$ getiriyle karşılaşmışlardır. Bir önceki olay tarihinden farklı olarak ise hem endekse giren hem de giremeyen şirketlere olay gününden 5 gün önce yatırım yapan ve yatırımlarını 5 gün sonra sonlandıran tüm yatırımcılar negatif getirilerle karşılaşmışlardır.

Tablo 4'te sunulan sonuçlar, endekse giren şirketlerin pozitif kümülatif ortalama getiri sağlayamadıklarını, dahası bu şirketlere 11 günlük yatırım yapan yatırımcıların negatif getiri elde ettiklerini göstermiştir. Bu durum, sürdürülebilirlik endeksine dahil edilmenin kümülatif pozitif bir tepkiyle karşılaşmadığını ortaya koymuştur. Buna karşılık, endekse dahil edilmeyen şirketlere karşı oluşan negatif tepki dikkat çekmektedir. Ayrıca 2018 yılında bir önceki yıla göre bu tepkide bir artış yaşanmıştır. $\mathrm{Bu}$ artış, her ne kadar endekse girişler pozitif bir getiri sağlamasa dahi, sürdürülebilirlik konusunda yatırımcıların duyarlılıklarında bir önceki yıla göre artış gerçekleştiğini göstermektedir.

\section{Sonuç, Tartışma ve Öneriler}

Ele alınan iki farklı olay gününde, sürdürülebilirlik endeksine dâhil edilmenin hem şirketler bazında hem de ortalamalar dikkate alındığında kesin bir şekilde pozitif ya da negatif getiri sağlamadığı tespit edilmiştir. Özellikle kümülatif ortalama anormal getiri sonuçları, hiçbir olay penceresinde pozitif normalüstü getirinin oluşmadığını kanıtlamaktadır. Bu sonuçlar, Curran ve Moran (2007) ile Ortas ve Moneva'nın (2011) elde etmiş oldukları sonuçlarla benzerlik göstermekte ve sürdürülebilirlik endeksine dâhil edilmenin pozitif getiri sağlayacağı hipotezini desteklememektedir. $\mathrm{Bu}$ noktada, Borsa İstanbul için sosyal sorumlu yatırımcıların şirketlerin piyasa değerleri üzerinde özellikle pozitif anlamda güçlü bir etkisinin bulunmadığı söylenebilir.

İncelenen olay günlerinde, endekse dâhil edilmemenin ise şirketler nezdinde negatif anlamlı ortalama getirilere sebep olduğu, bu negatif ortalama getirilerin 27.10.2017 tarihinde uzun süre varlığını koruduğu, 26.10.2018 tarihinde ise daha kısa sürede normale döndüğü ortaya konulmuştur. Ortalama anormal getiri hesaplamaları göz önünde bulundurulduğunda, sürdürülebilirlik ile ilgili çıkan olumsuz haberlerin yatırımcılar tarafından negatif bir tepki ile karşılandığı söylenebilmektedir. Ayrıca bu durum her iki olay penceresine ait hesaplanan kümülatif ortalama anormal getiriler üzerinden de ortaya konulabilmektedir. Ulaşılan bu bulgu, Lorraine vd.'nin (2004) araştırmasını destekler niteliktedir. Her ne kadar, Lorraine vd. (2004) tarafından yapılan çalışmada şirketlerin sürdürülebilirlik performansları yalnızca çevresel performansları üzerinden ölçülmüş olsa da sonuçta yatırımcların ortaya çıkan olumsuz haberlere negatif bir tepki verdikleri açıktır.

Elde edilen sonuçlar, sürdürülebilirlik endeksine dâhil edilmenin kesin bir pozitif ya da negatif tepkiyle karşılanmamasına karşın endekste yer alamamanın negatif bir tepkiyle karşılandığını göstermekte ve bu açıdan Becchetti vd. (2012) ve Consolandi vd. (2009) tarafindan yapılan çalışmalarla benzer sonuçlar içermektedir. Ayrıca, endekse giremeyen şirketlere ait oluşan negatif kümülatif getirilerin 2018 yılında bir önceki yıla göre artış göstermiş olması, yatırımcılar arasında sosyal sorumluluk kavramının benimsenmiş olduğuna işaret etmekte ve Nakai vd.'nin (2013) çalışmasını desteklemektedir. Buna göre, ilerleyen yıllarda yatırımcıların sürdürülebilirlik konusuna olan hassasiyetlerinin artacağı ve dolayısıyla endekse dahil edilen şirketlere karşı pozitif kümülatif getiri oluşacağ

Özellikle gelişmiş piyasalarda yatırımcıların sürdürülebilirlikle ilgili olumlu durumlara pozitif, olumsuz durumlara ise negatif tepki verdiği ortaya konulmuştur. Ancak gelişmekte olan piyasalarda da benzer sonuçların ortaya çıkabilmesi ancak yatırımcıların sürdürülebilirlik konusunda yeterli bilgiye sahip olması, sürdürülebilirlik konusunu önemsemesi ve piyasanın etkin bir yapıya kavuşmasıyla sağlanacaktır (Adamska ve Dabrowski, 2016, s. 368). Yapılmış pek çok çalışmada, yatırımcıların sürdürülebilir yahut sosyal sorumlu olarak adlandırılan yatırımlar hakkında henüz çok bilgi sahibi olmadığ tespit edilmiş olmakla birlikte, Türkiye'de bu alanda yapılmış herhangi bir çalışma bulunmamaktadır. Sürdürülebilirlik endeksi, sosyal sorumlu yatırımlar, sürdürülebilir yatırım araçları vb. konularda düzenleyici kurum ve kuruluşların yaptığ çalışmalar ise oldukça sınırlı ve yatırımcıya ulaşmaktan oldukça uzaktır. Türkiye'de yapılan araştırmalarda, Consolandi vd. (2009), Reddy ve 
Gordon (2010) ve Robinson vd. (2011) tarafindan ulaşılan bulgularla uyumlu sonuçların elde edilememesinin temel nedeni yukarıda sayılan faktörlerden dolayı yatırımcıların henüz tam olarak sürdürülebilir yatırım anlayışına kavuşamamış olmalarıdır.

Bu çalışmada, Sürdürülebilirlik Endeksi’ne dâhil edilmek üzere incelemeye alınan ve bir yıllık inceleme sonucu endekse giren ve giremeyen şirketlere yönelik yatırımcı tepkisi incelenmiştir. Alanda yapılacak çalışmaların, sürekli olarak endekste yer alan şirketlere ve endeksten çıkarılan şirketlere karşı oluşan tepkileri incelemesi faydalı olacaktır. Bunun yanında, yatırımcı düşünceleri ve davranışlarını ölçmeye odaklanan çalışmalar literatürdeki boşluğu doldurmak adına faydalı olacaktır. Ayrıca, uluslararası piyasalarda kullanılan sosyal sorumlu yatırım araçlarının tespit edilmesi ve Türkiye'de kullanılabilirliklerinin test edilmesi konusunda çalışmalar yapılmasının gerekliliği de ortadadır.

\section{Kaynaklar}

Adamska, A. and Dabrowski, T. J. (2016). Do investors appreciate information about corporate social responsibility? Evidence from the Polish equity market. Inzinerine Ekonomika/Engineering Economics, 27(4), 364-372.

Adriani, F. and Becchetti, L. (2002). Fair trade: A "third generation welfare" mechanism to make globalisation sustainable (Ed.) Whalley, J. Working Paper, No. 171.

Altınay, A., Kaki, B., Kestane, A., Soba, M., Dinçer, Ö. ve Eser, Ş. I. K. (2017). Sürdürülebilirlik endeksinin bankacılık sektörü hisse senedi değerlerine etkileri, BİST Sürdürülebilirlik Endeksi üzerine bir inceleme. Sosyal Ekonomik Araştırmalar Dergisi, 17(34), 208-229. DOI: 10.30976/susead.337089

Bash, A. and Alsaifi, K. (2019). Fear from uncertainty: An event study of Kashoggi and stock market returns. Journal of Behavioral and Experimental Finance, 23, 54-58.

Becchetti, L., Ciciretti, R., Hasan, I. and Kobeissi, N. (2012). Corporate social responsibility and shareholder's value. Journal of Business Research, 65(11), 1628-1635. https://doi.org/10.1016/j.jbusres.2011.10.022

Becchetti, L., Di Giacomo, S. and Pinnacchio, D. (2008). Corporate social responsibility and corporate performance: Evidence from a panel of US listed companies. Applied Economics, 40(5), 541567. https://doi.org/10.1080/00036840500428112

BİST Duyurular, https://www.borsaistanbul.com/duyurular adresinden 04.02.2019 tarihinde erişilmiştir.

Borsa İstanbul. (2014). Şirketler İçin Sürdürülebilirlik Rehberi. https://www.borsaistanbul.com/data/kilavuzlar/surdurulebilirlik-rehberi.pdf

Borsa İstanbul, Endeks ve Veri Direktörlüğü 1:13, BIST Sürdürülebilirlik Endeksi Temel Kuralları, (2017). http://www.borsaistanbul.com/docs/default-source/endeksler/bist-surdurulebilirlikendeksi-temel-kurallari.pdf?sfvrsn=23 adresinden erişilmiş̧tir.

Brown, S. J. and Jerold, B. W. (1980). Measuring security price performance. Journal of Financial Economics, 8(3), 205-258. https://doi.org/10.1016/0304-405X(80)90002-1

Cheung, A. and Roca, E. (2013). The effect on price, liquidity and risk when stocks are added to and deleted from a sustainability index: Evidence from the Asia Pacific context. Journal of Asian Economics, 24, 51-65. https://doi.org/10.1016/j.asieco.2012.08.002 
Consolandi, C., Jaiswal-Dale, A., Poggiani, E. and Vercelli, A. (2009). Global standards and ethical stock indexes: The case of the Dow Jones Sustainability Stoxx Index. Journal of Business Ethics, 87(1), 185-197. https://doi.org/10.1007/s10551-008-9793-1

Curran, M. M. and Moran, D. (2007). Impact of the FTSE4Good Index on firm price: An event study. Journal of Environmental Management, 82(4), 529-537.

Çıtak, L. ve Ersoy, E. (2016). Firmaların BIST Sürdürülebilirlik Endeksine alınmasına yatırımcı tepkisi: Olay çalışması ve ortalama testleri ile bir analiz. International Journal of Alanya Faculty of Business, 8(1), 43-57.

Çiftçioğlu, B. A. ve Gök, B. (2018). Kurumsal sosyal sorumluluğun kurumsal itibara etkisi ve bir uygulama. Ahi Evran Üniversitesi Sosyal Bilimler Enstitüsü Dergisi, 4(2), 183-196.

Daszyńska-Żygadło, K., Ryszawska, B., Słoński, T. and Zawadzki, B. M. (2014). Investors’ reactions for sustannability index inclusion-Is CSR a good news?. Acta Universitatis Lodziensis Folia Oeconomica, 2(300), 45-60

Domini, A. L. (2001). Socially responsible investing: Making a difference and money. Chicago, USA: Dearborn Trade.

Faramarzi, A. and Bhattacharya, A. (2021). The economic worth of loyalty programs: An event study analysis. Journal of Business Research, 123, 313-323.

Gök, İ. Y. ve Gökşen, H. (2020). Bankaların sürdürülebilirlik endeksine dahil edilmelerinin hisse senedi getirileri üzerindeki etkisi. Süleyman Demirel Üniversitesi Vizyoner Dergisi, 11(26), 89-106.

Kamuyu Aydınlatma Platformu, Duyurular. (2019). https://www.kap.org.tr/tr/ara/s\%C3\%BCrd\%C3\%BCr\%C3\%BClebilirlik\%20endeksi/1 adresinden 10.08.2019 tarihinde erişilmiştir.

Kim, J., Kim, J., Lee, S.K. and Thang, L. (R) (2020). Effects of epidemic disease outbreaks on financial performance of restaurants: Event study method approach. Journal of Hospitality and Tourism Management, 43, 32-41.

Klassen, R. D. and McLaughlin, C. P. (1996). The impact of environmental management on firm performance. Management Science, 42(8), 1199-1214. https://doi.org/10.1287/mnsc.42.8.1199

Lorraine, N. H. J., Collison, D. J. and Power, D. M. (2004). An analysis of the stock market impact of environmental performance information. Accounting Forum, 28(1), 7-26. https://doi.org/10.1016/j.accfor.2004.04.002

McWilliams, A. and Siegel, D. (2000). Corporate social responsibility and financial performance: Correlation or misspecification?. Strategic Management Journal, 21(5), 603-609. https://doi.org/10.1002/(SICI)1097-0266(200005)21:5<603::AID-SMJ101>3.0.CO;2-3

Nakai, M., Yamaguchi, K. and Takeuchi, K. (2013). Sustainability membership and stock price: An empirical study using the Morningstar-SRI Index. Applied Financial Economics, 23(1), 71-77. https://doi.org/10.1080/09603107.2012.709602

Oberndorfer, U., Schmidt, P., Wagner, M. and Ziegler, A. (2013). Does the stock market value the inclusion in a sustainability stock index? An event study analysis for German firms. Journal of Environmental Economics and Management, 66(3), 497-509. https://doi.org/10.1016/j.jeem.2013.04.005 
Ortas, E. and Moneva, J. M. (2011). Sustainability stock exchange indexes and investor expectations: Multivariate evidence from DJSI-Stoxx. Spanish Journal of Finance and Accounting, 40(151), 395-416. https://doi.org/10.1080/02102412.2011.10779706

Pandey, D.K. and Kumari, V. (2020). Event study on the reaction of of the developed and emerging stock markets to the 2019-nCoV outbreak. International Review of Economics and Finance, 71, 467-483.

Reddy, K. and Gordon, L.W. (2010). The effect of sustainability reporting on financial performance: An empirical study using listed companies. Journal of Asia Entrepreneurship and Sustainability, 6(2), 19-42.

Renneboog, L., Ter Horst, J. and Zhang, C. (2008). Socially responsible investments: Institutional aspects, performance and investor behaviour. Journal of Banking and Finance, 32(9), 1.7231.742. https://doi.org/10.1016/j.jbankfin.2007.12.039

Robinson, M., Kleffner, A. and Bertels, S. (2011). Signaling sustainability leadership: Empirical evidence of the value of DJSI membership. Journal of Business Ethics, 101(3), 493-505. https://doi.org/10.1007/s10551-011-0735-y

Scholtens, B. and Peenstra, W. (2009). Scoring on the stock exchange? The effect of football matches on stock market returns: An event study. Applied Economics, 41(25), 3231-3237.

Temiz, H. ve Acar, M. (2018). Sürdürülebilirlik endeksinde işlem gören firmaların finansal performansı: olay çalışması örneği. Hitit Üniversitesi Sosyal Bilimler Enstitüsü Dergisi, 11(3), 1971-1987. Doi: 10.17218/hititsosbil.441200

The Global Sustainable Investment Alliance, Global Sustainable Investment Review (2018). https://www.ussif.org/files/GSIR_Review2018F.pdf

Tükenmez, N. M. ve Gençyürek, A. G. (2016). Sustainability indices in developing markets: A study about Borsa Istanbul Sustainability Index. Journal of Accounting, Finance and Auditing Studies, 2(2), 39-69.

Yavuz, S., Yıldırım, S. ve Elmas, B. (2015). Kurumsal yönetim endeksi ile şirket hisse senedi getiri ilişkisi: BİST’te bir uygulama, Erzincan Üniversitesi Sosyal Bilimler Enstitüsü Dergisi, 8(2), 73-82.

Yue, W., Zhang, S. and Zhang, Q. (2020). Asymmetric news effects on cryptocurrency liquidity: An Event study perspective. Finance Research Letters. DOI: 10.1016/j.frl.2020.101799. 


\section{Extended Abstract}

\section{Introduction}

The development of sustainable investments, also known as ethical investment or social responsible investment, allows investors to compare their investment policies with their personal values and principles (Domini, 2001; Ortas and Moneva, 2011, s. 396). Today, there is a great interest in sustainable investments. As a result of increased interest in sustainability, investors have started to take into account the sustainability performance of the companies as well as obtaining the best return. Thus, how investors reacted to the inclusion and exclution of firms' stocks from index became one of the researched topics. This research aimed to reveal the direction and the degree of the investor response to the companies that included and not on the BIST Sustainability Index. In the research by using the case study method, analyzes were carried out over two different years in order to measure the investors response better. In addition, to detect both positive and negative responses, the returns of firms that are listed and not in the index after the evaluation are examined separately. The results show that inclusion in the sustainability index is not met with a definite positive or negative response, but the failure of inclusion in the index is met with a negative response.

\section{Literature Review}

When the literature is reviewed, besides the studies showing there is a linear relationship between the social responsibility performances of the companies and their financial performances (Consolandi, Jaiswal-Dale, Poggiani and Vercelli 2009; Klassen and Laughlin, 1996; Lorraine, Collison and Power 2004; Reddy and Gordon, 2010) there are also studies showing that the society is indifferent to the environmental and social performance of the companies (Curran and Moran, 2007; Ortas and Moneva, 2011). In addition, it was determined that responses to news that can be considered negative in the stock market is stronger and more permanent then the responses to positive news (Consolandi et al., 2009).

Some studies have shown that only positive returns ocur after positive news and investors are indifferent to negative news (Nakai, Yamaguchi and Takeuchi, 2013). However, this happened in the opposite way in different markets, while negative news faced negative reaction, positive news remained unresponsive (Becchetti, Ciciretti, Hasan and Kobeissi 2012). In Turkey, the number of studies in this area are limited and while the effect of positive news is researched, the effect of negative news is generally ignored. The reviewed literature shows that the effect of positive news on stocks is mostly not significant (Altınay, Kaki, Kestane, Soba, Dinçer and Eser 2017; Çıtak and Ersoy, 2016; Temiz and Acar, 2018; Tükenmez and Gençyürek, 2016).

\section{Method}

The "Event Analysis" method was used to investigate whether there are significant changes in the returns of the firms after announcing whether companies are included in the BIST Sustainability Index or not. In this method, the day of the announcement was accepted as the "event day" and it was evaluated whether company shares provided abnormal returns in the days following the event day.

The data to be used in the analysis are the end-of-day closing data of the companies those were evaluated for the first time to be included in the BIST Sustainability Index for 2018 and 2019 and were obtained through Bloomberg Terminal.

\section{Results}

In the study, two different dates were considered as the event day. These dates are 27.10.2017 and 26.10.2018. The announcement of firms including or not in the XUSRD for each period is accepted as an independent event. Therefore, 4 different event analyzes were carried out. 
When the average abnormal returns calculated by considering the averages are analyzed, it is seen that firms are announced to be not included in the index provide a higher number of average abnormal returns compared to the firms included in the index. This finding is in line with the general belief that negative informations in financial markets are more responsive then positive informations. When the cumulative average abnormal returns are calculated, it is determined that firms included in the index are not able to provide a positive cumulative average return. On the other hand, the negative reaction against firms not included in the index is remarkable. In addition, this reaction has increased in 2018 compared to the previous year. This increase shows that investors' sensitivity on sustainability has increased compared to the previous year, even if the including on the index do not yield a positive return.

\section{Discussion and Conlusion}

The results show that inclusion in the sustainability index is not met with a definite positive or negative response, but the failure of inclusion in the index is met with a negative response and in this respect, contains similar results to those conducted by Consolandi et al. (2009) and Becchetti et al. (2012). Moreover, the fact that the negative cumulative returns of companies that is not included in the index increased in 2018 indicates that the concept of social responsibility among investors has been adopted and this result supports the research of Nakai et al. (2013).

Even though several studies have suggested that investors not yet have much information about sustainable investment, there are no studies focusing on this area in Turkey. The studies carried out by regulatory institutions and organizations on issues such as sustainability index, socially responsible investments, and sustainable investment instruments are very limited and far from reaching the investors. In this context, studies focusing on measuring investor thoughts and behaviors will be useful to fill the gap in the literature. In addition, new researchs should be done about the identification of socially responsible investment instruments used in the international market and use of these instruments in Turkey. 